\title{
ReaxFF Molecular Dynamics Simulation Study of Nanoelectrode Lithography Oxidation Process on Silicon (100) Surface
}

\author{
Rashed Md. Murad Hasan ${ }^{1}$, Olivier Politano ${ }^{2}$, and Xichun Luo*,1 \\ ${ }^{1}$ Centre for Precision Manufacturing, Department of Design, Manufacture and Engineering Management, \\ University of Strathclyde, Glasgow G1 1XJ, United Kingdom \\ ${ }^{2}$ ICB, Université de Bourgogne, UMR 6303 CNRS, 9 Avenue A. Savary, Dijon, France \\ *Correspondence to: Xichun Luo, Department of Design, Manufacture and Engineering Management, \\ University of Strathclyde, United Kingdom.E-mail address: xichun.luo@strath.ac.uk
}

\begin{abstract}
:
The nanoelectrode lithography has been strengthened in recent years as one of the most promising methods due to its high reproducibility, low cost and ability to manufacture nanosized structures. In this work, the mechanism and the parametric influence in nanoelectrode lithography have been studied qualitatively in atomic scale using ReaxFF MD simulation. This approach was originally developed by van Duin and co-workers to investigate hydrocarbon chemistry. We have investigated the water adsorption and dissociation processes on $\mathrm{Si}$ (100) surface as well as the characteristics (structure, chemical composition, morphology, charge distribution, etc.) of the oxide growth. The simulation results show two forms of adsorption of water molecules: molecular adsorption and dissociative adsorption. After breaking the adsorbed hydroxyls, the oxygen atoms insert into the substrate to form the $\mathrm{Si}-\mathrm{O}-\mathrm{Si}$ bonds so as to make the surface oxidized. The influence of the electric field intensity $(1.5-7 \mathrm{~V} / \mathrm{nm})$ and the relative humidity $(20-90 \%)$ on the oxidation process have also been discussed. Nevertheless, the results obtained from the simulations have been compared qualitatively with the experimental results and they show in good agreements. Variable charge molecular dynamics allowed us to characterize the nanoelectrode lithography process from an atomistic point of view.
\end{abstract}

Keywords: ReaxFF MD, Oxidation, Chemical composition, Electric field intensity, Humidity

\section{Introduction}

Local oxidation-based nanolithography techniques have attracted a great deal of attention, since the first report of silicon oxidation by using a scanning tunneling microscope (STM) as a lithography tool by Dagata et al. [1]. Many groups have tried a number of studies to understand the physical and chemical phenomena involved in the process. Sugimura and his collaborators [2][3] reported that the oxides produced with the STM were the result of an 
electrochemical reaction in which the water absorbed at the tip of the microscope and on the surface of the sample. During the last decades, atomic force microscope (AFM) based local oxidation was used as an efficient lithographic technique which was capable of manufacturing nanometer-sized devices on the various surfaces [4][5][6][7]. Recently, a great number of studies have been carried out that paved the way for the development and expansion of local oxidation approaches to modify surfaces [8][9][10][11][12]. However, AFM based method is not suitable for large area fabrication due to its limitation in processing speed. To overcome this limitation some groups proposed and demonstrated a method which includes a conductive stamp with multiple protrusions as the cathode electrode instead of AFM/STM tip [13][14][15]. It is showed that local oxidation can be effectively used with these stamps brought into intimate contact with different substrates: silicon [16][17][18], GaAs [19][20] and pentacene layers [21]. This method is known as Parallel local oxidation nanolithography or Nanoelectrode lithography (NEL).

The NEL process consists of some physical and chemical processes such as condensation, electric field effects, ionic transport, water dissociation, and oxidation. The principle of NEL process is illustrated in Figure 1. Under humid environment, a significant amount of water molecules is adsorbed on both stamp and sample surfaces. When the protrusive parts of the stamp are in contact with the substrate, the vicinity of both surfaces can trigger spontaneous capillary condensation and a water meniscus will be formed between them [22] and a current flows into the water meniscus. The strong electric flux from the protrusive parts of the stamp to the substrate results in the decomposition of water molecules into oxyanions $\left(\mathrm{OH}^{-}, \mathrm{O}^{-}\right)$and protons $\left(\mathrm{H}^{+}\right)$. These ions penetrate the substrate to form an oxide film on the surface. Subsequently, the substrate is etched to achieve nanostructures like other methods.

(a)

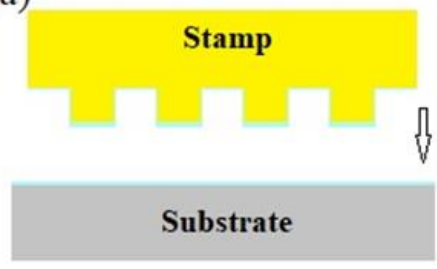

(b)

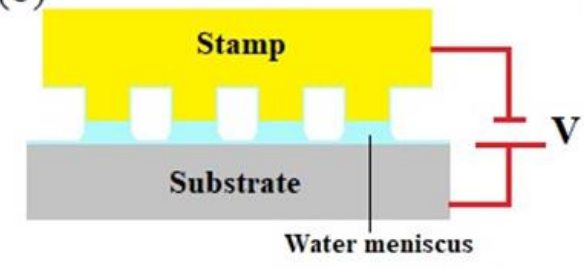

(c)

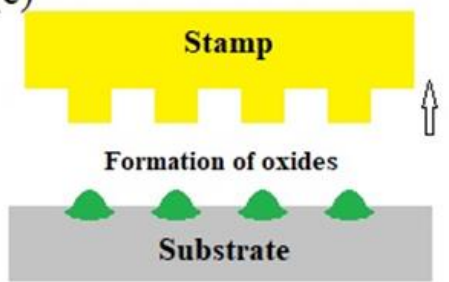

Figure 1. Diagram of the NEL process. (a) A thin layer of water adsorbed on top of the surfaces. (b) An electric field is applied between the two surfaces. (c) The water meniscus induces the formation of oxides on the substrate surface through the process of anodic oxidation. 
Simulations were performed by using different methods to obtain an in-depth understanding of the oxidation process and microstructure evolution [23][24][25]. Simulation on the formation of a water bridge induced by an electric field described a molecular explanation for the threshold voltage and hysteresis behavior observed in the formation of nanoscale liquid bridges [26]. Christopher D. Daub et al. explained the sensitivity of water droplet contact angles to the applied electric field polarity and direction relative to the liquid/solid interface by using MD simulation [27]. Despite several simulation efforts on exploring the effect of electric field on water bridge formation and the oxidation mechanism, the process has not been fully investigated in molecular level. After the development of a new reactive force field (ReaxFF) by the group of Adri van Duin [28], it is possible to study the reactivity of materials by using a ReaxFF MD simulation via a sophisticated bond-order potential. In recent years, ReaxFF MD simulations have been utilized to investigate the thermal oxidation of Si surfaces including nano-oxidation [29][30][31], initial stage oxidation [32][33][34] and dry-oxidation [35]. Among these works, the oxidation processes were systematically studied, as well as the temperature effect, orientation effect, interfacial interaction and stress evolution.

In the present work, ReaxFF MD simulations have been employed to investigate the NEL process. We studied the oxidation mechanism of Si (100) substrate under an applied electric field in humid air at room temperature. The Si (100) substrates have been a good model to demonstrate some of the fundamental aspects that are involved in the oxidation process. We have assessed the structural and morphological features related to the growth of the oxide film. Several experimental parameters influence the NEL process. Applied voltage, exposure time and relative humidity $(\mathrm{RH})$, are the important kinetic factors in oxidation reactions. We have investigated the effect of these parameters on oxide growth. The next sections of this paper are organized as follows. In section 2 the computational details and the setup of the system is described. Section 3 presents the molecular dynamics simulation results and discussions which includes the oxidation mechanism as well as the influence of electric field intensity and the humidity on the oxidation process. Finally, in section 4 conclusions are summarized.

\section{Computational details}

The force field parameters used in this study were developed by Jialin Wen et al. [36] based on the combination of the $\mathrm{Si} / \mathrm{Ge} / \mathrm{H}$ force field [37] with the water force field [38]. These parameters have been validated and used to investigate the interaction of silicon with water and tribochemical wear mechanism of silicon which showed good agreement with the 
experimental results [36][31]. The charge equilibration (QEq) model as described in [39][40] has been used in conjunction with the ReaxFF force field to equilibrate charge of the system at each time step. All the simulations have been conducted by the "Large-scale Atomic/Molecular Massively Parallel Simulator" (LAMMPS) code [41] with a modification done by O. Assowe et al. [42]. To introduce the electric field, they modified the Coulomb energy term in the ReaxFF potential by using the formula proposed by Chen and Martinez [43]. The electrostatic energy was modified to consider electronegativity differences and charge conservation. To construct the model, we consider a silicon substrate of 1500 atoms with the size of $38.4009 \AA \times 38.4009 \AA \times 18.42 \AA$. A 10 - $\AA$-thick water layer (490 molecules), which corresponds to a relative humidity of $~ 90 \%$ [44], is placed on top of the $\mathrm{Si}$ substrate. We have introduced a reflecting wall to confine water molecules on the top of the substrate. We have applied an external electrical field between the Si substrate and the reflecting wall in order to mimic the presence of a conductive stamp on the top of the surface.

The size of the simulation model box is $38.4009 \times 38.4009 \times 34.2537 \AA^{3}$. Periodic boundary conditions have been applied along both $\mathrm{x}$ and $\mathrm{y}$ directions, and shrink-wrapped boundary condition has been applied along the z-direction. The side view of the simulation model is shown in Figure 2. Atoms with orange color represent the silicon. Red and white atoms are Oxygen and Hydrogen, respectively. We have relaxed the silicon substrate to stable the configuration at room temperature $(300 \mathrm{~K})$ using NVE ensemble with the Berendsen thermostat for 50 picoseconds with a damping constant of 25 femtoseconds. All other simulations have used NVT ensemble with the Nose-Hoover heat bath at a time step of 0.1 femtoseconds and the temperature has been controlled to be $300 \mathrm{~K}$ with a damping constant of 10 femtoseconds. Verlet algorithm has been adopted to integrate the atom trajectories. Snapshot pictures have been produced using OVITO [45]. 


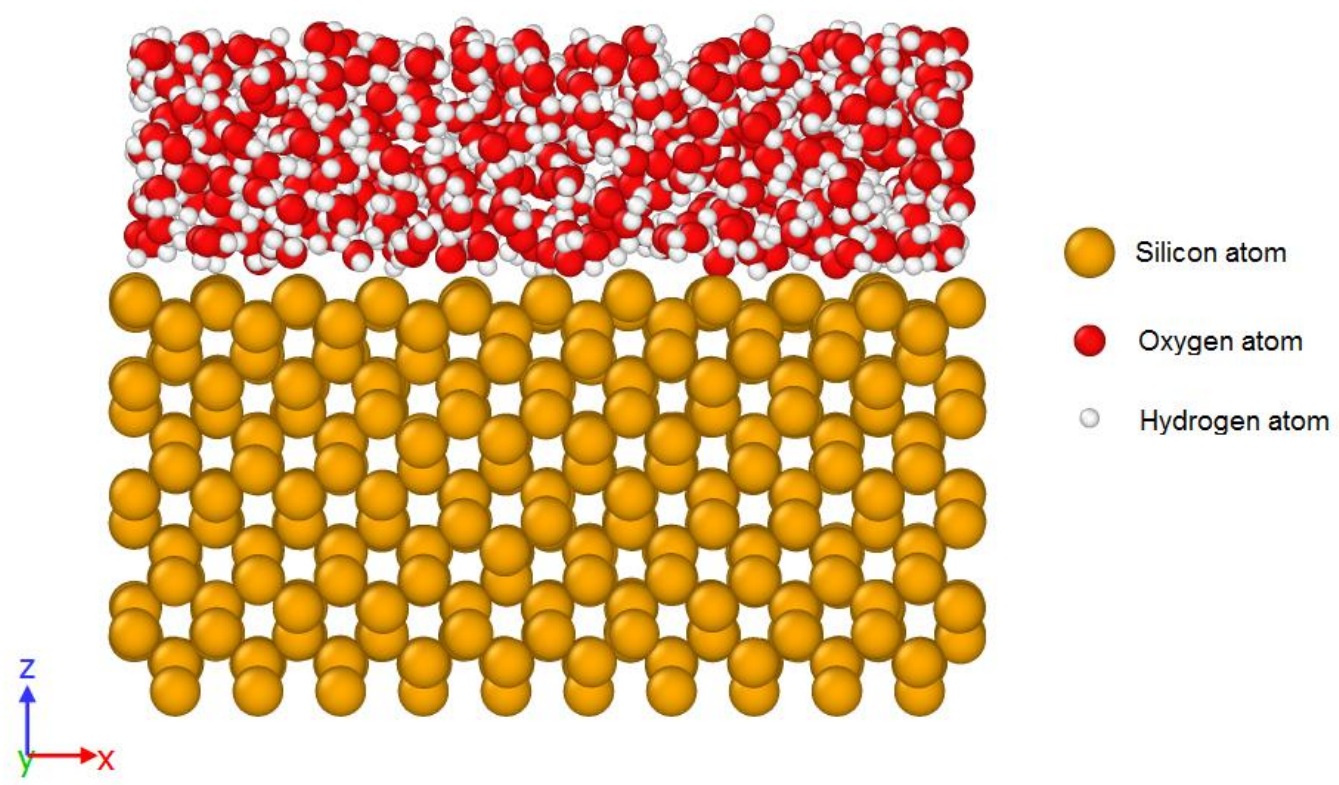

Figure 2. Simulation model

\section{Results and Discussions}

3.1 Analysis of the oxidation process

We have applied an electric field of $2 \mathrm{~V} / \mathrm{nm}$ between the reflecting wall and the substrate to understand the oxidation mechanism as the minimum electrical field required to polarize and pull the water molecules adsorbed on the surface towards the stamp is $\sim 1.3 \mathrm{~V} / \mathrm{nm}$ [46]. Figure 3 shows the snapshot details at the end of the simulation (400 ps) at $300 \mathrm{~K}$. We have observed the adsorption and the dissociation of water on the Si surfaces as well as the formation of an oxide film.
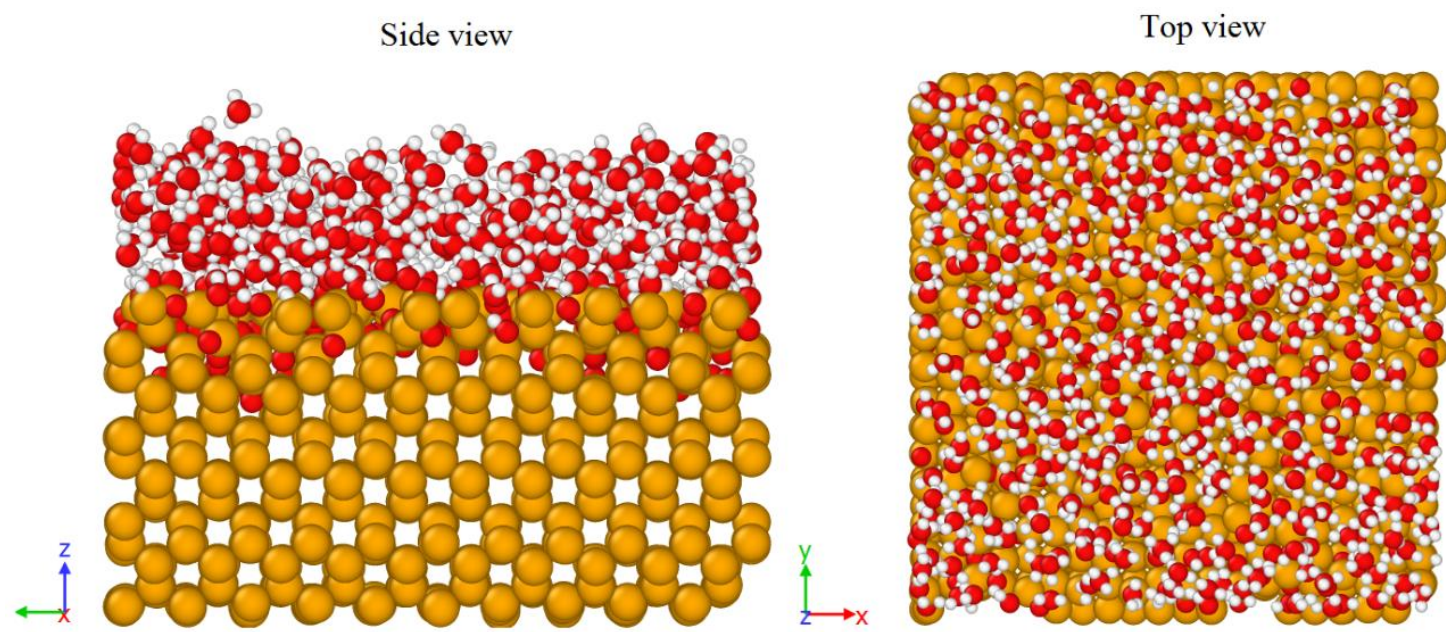

Figure 3. Side view and top view of the system after $400 \mathrm{ps}$ of simulation 


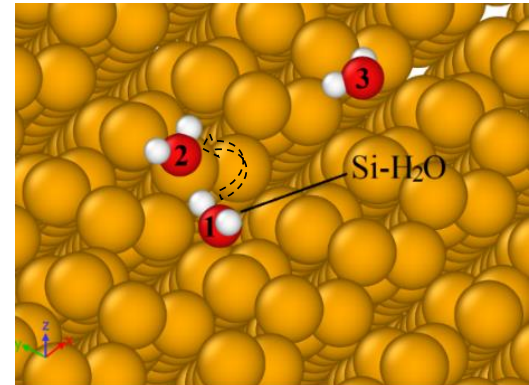

(a) $0.5 \mathrm{ps}$

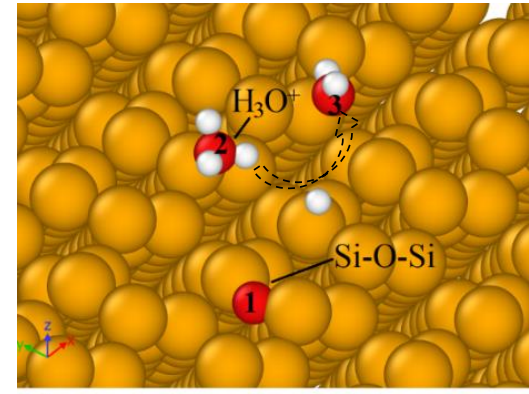

(c)
$1 \mathrm{ps}$

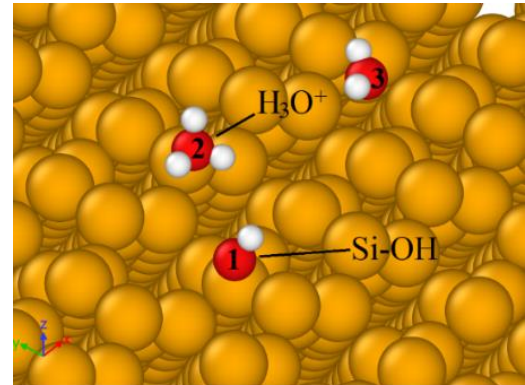

(b)

$0.75 \mathrm{ps}$

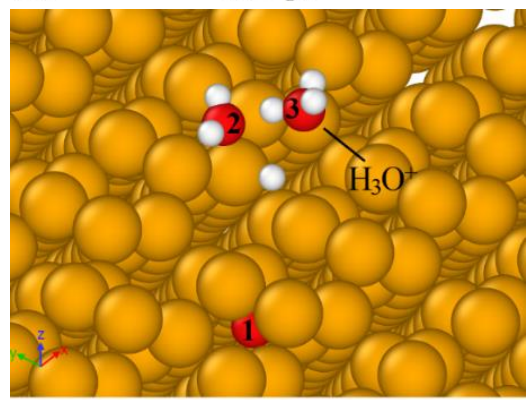

(d)

Figure 4. The interaction between $\mathrm{H}_{2} \mathrm{O}$ and $\mathrm{Si}$ (100) substrate surface. (a) Three water molecules in which one water molecule (numbered 1) adsorbed on the Si substrate surface. (b) Dissociation of water and the formation of $\mathrm{Si}-\mathrm{OH}$ and $\mathrm{H}_{3} \mathrm{O}^{+}$. (c) Proton transfer process between two adjacent water molecules.

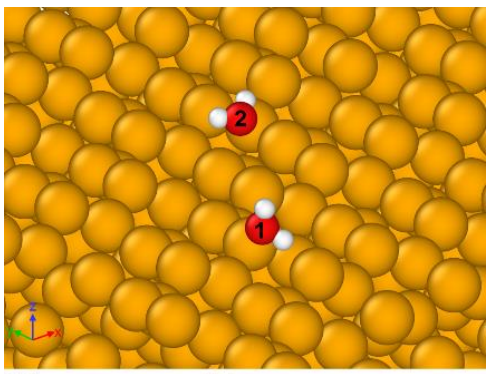

(a)

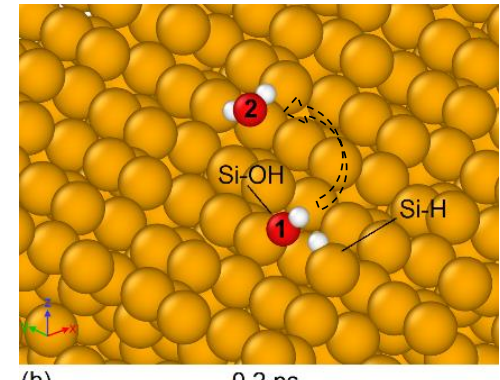

(b)

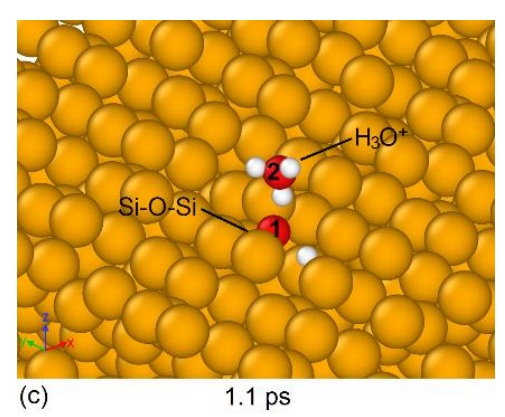

Figure 5. (a) Two water molecules on the Si substrate surface. (b) Formation of $\mathrm{Si}-\mathrm{H}$ and $\mathrm{Si}-\mathrm{OH}$. (c) Bond breaking of $\mathrm{S}-\mathrm{OH}$ to form $\mathrm{Si}-\mathrm{O}-\mathrm{Si}$ and $\mathrm{H}_{3} \mathrm{O}^{+}$formation.

To explain the oxidation process we visualize only a few water molecules on the silicon surface in Figure 4 and 5. After 0.5 picoseconds, the water molecule (numbered 1) is adsorbed on the silicon surface shown in Figure 4(a). Then the water molecule is dissociated into ions $\left(\mathrm{OH}^{-}\right.$and $\left.\mathrm{H}^{+}\right)$to form a $\mathrm{Si}-\mathrm{OH}$ bond and the proton $\left(\mathrm{H}^{+}\right)$goes to a nearby water molecule (numbered 2) to form hydronium, $\mathrm{H}_{3} \mathrm{O}^{+}$(Figure 4b). The average charge of $\mathrm{OH}^{-}$ and $\mathrm{H}_{3} \mathrm{O}^{+}$are observed as $-0.237 e$ and $+0.285 e$, respectively. Subsequently, there is a breaking of $\mathrm{Si}-\mathrm{OH}$ bond and the oxygen atom has occupied the space between the silicon atoms that leads to the formation of $\mathrm{Si}-\mathrm{O}-\mathrm{Si}$ bond (Figure 4c). Again, the proton is transferred from the second water molecule to the third one, as shown in Figure 4(d). We have observed an increase in the average charge of surface silicon atoms while the chemical 
reactions. For an arbitrary silicon atom, the charge is $+0.125 e$ at 0.5 picoseconds where it increases to +0.237 e just after bond breaking with an $\mathrm{OH}^{-}$at 0.6 picoseconds .

However, it is also observed that the water molecule can dissociate directly which forms $\mathrm{Si}-$ $\mathrm{H}$ and $\mathrm{Si}-\mathrm{OH}$ bonds as demonstrated in Figure 5a, b. After a period (at $1.1 \mathrm{ps}$ ), the hydroxyl of $\mathrm{Si}-\mathrm{OH}$ decomposes into oxygen and hydrogen atom and the oxygen atom combines with silicon atoms to form $\mathrm{Si}-\mathrm{O}-\mathrm{Si}$ bond (Figure 5c). Here we also notice $\mathrm{H}_{3} \mathrm{O}^{+}$formation. The above-explained oxidation processes were also previously observed experimentally for thermal oxidation of silicon (100) surface [47][48]. This oxidation process is being repeated itself over time that develop an oxide film on the silicon surface. Figure 6 depicts the evolution of the thickness of the oxide film throughout the simulation which displays the several layers of oxide height. The oxide growth experiences a rapid surge at the very beginning and reaches to more than $2 \AA$ within 2 picoseconds. Then the oxide height shows a steady but significant increase over the period until a quick rise at 13 picoseconds to reach the first significant layer $(\sim 4.8 \AA)$. We have calculated the Si/O stoichiometry of 4.45 at 11 picoseconds. Then it decreases gradually to 2.54 at 15 picoseconds which meaning the more filling of oxygen atoms in this layer. After that, the oxidation process seems to be slowed down. The reason for the slowness is the accumulation of ionic charges of oxides after its creation that effects the charge diffusion in the water meniscus [49]. This layer continues with a little fluctuation in oxide height until 315 picoseconds then there is an abrupt escalation to reach the next layer $(\sim 6 \AA)$. We also find the same decreasing behavior of the $\mathrm{Si} / \mathrm{O}$ stoichiometry in this layer with a higher value than that of the previous layer. The oxide growth continues with the presence of electric field.

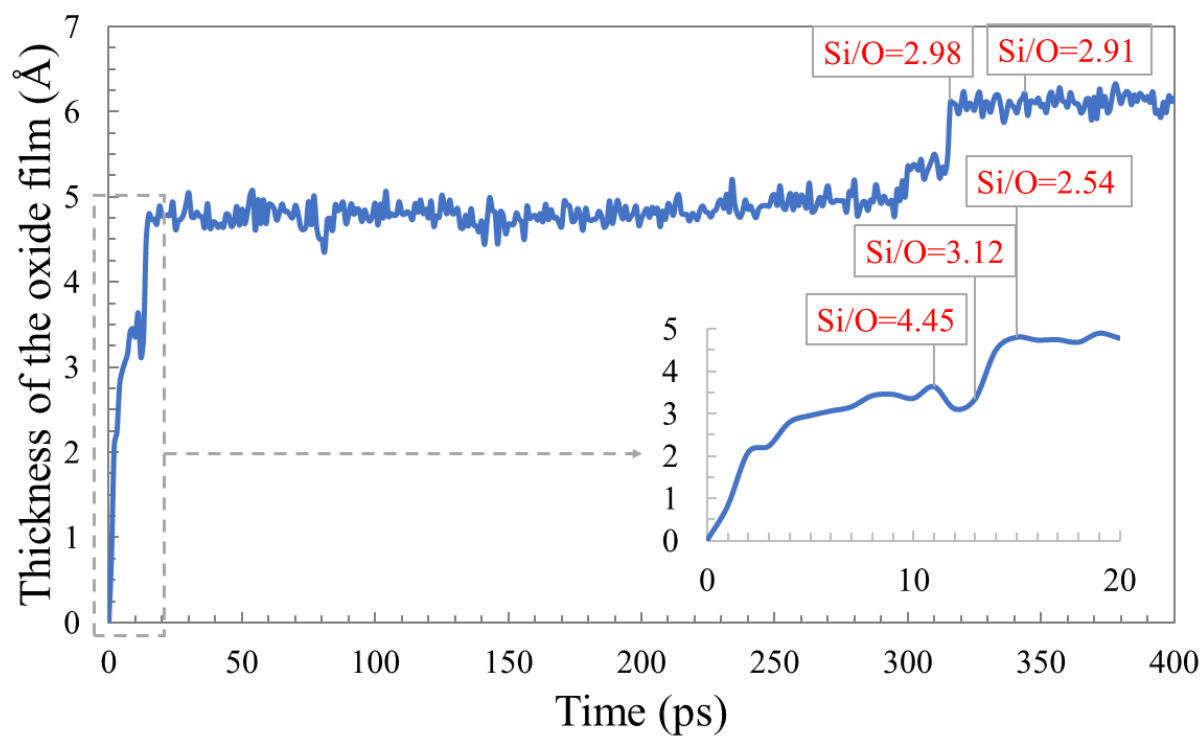


Figure 6. Evolution of oxide film for an electric field of $2 \mathrm{~V} / \mathrm{nm}$.

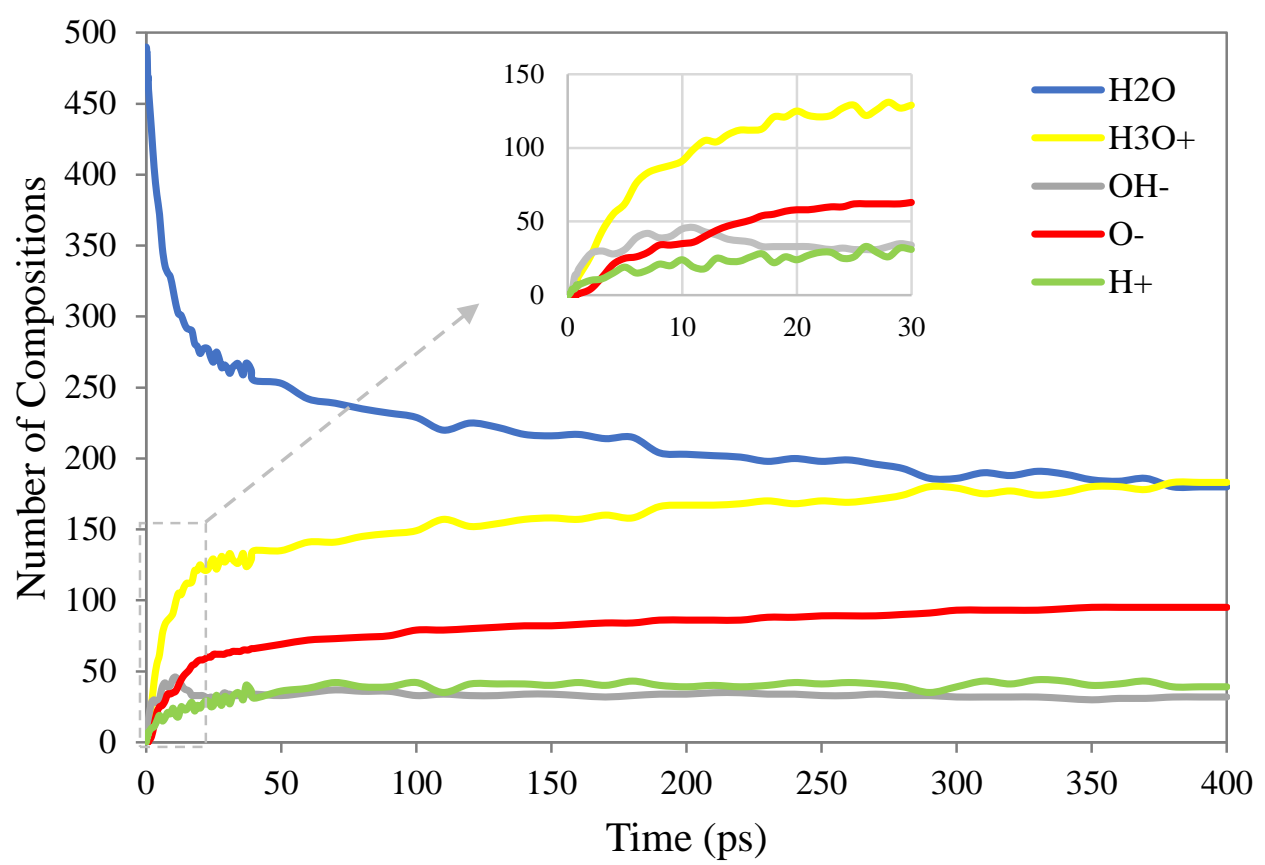

Figure 7. Evolution of chemical compositions for an electric field of $2 \mathrm{~V} / \mathrm{nm}$.

The number of chemical compositions developed during simulations is shown in Figure 7. It has been seen that the number of water molecules decreases over time while the number of ions $\left(\mathrm{OH}^{-}, \mathrm{H}_{3} \mathrm{O}^{+}, \mathrm{O}^{-}, \mathrm{H}^{+}\right)$increases which is obvious as the water molecules dissociate into ions (Figure 4 and 5). There is a rapid increase of the ions at the beginning of the simulation which represents the quick oxide growth explained in Figure 6. After 11 picoseconds the amount of $\mathrm{OH}^{-}$starts to decrease gradually over time. The $\mathrm{OH}^{-}$combines with the silicon surface and then releases proton which eventually facilitates the formation of the oxide film. The proton recombines with the water molecules that gradually increases the number of $\mathrm{H}_{3} \mathrm{O}^{+}$ over time. After 20 picoseconds the oxidation process continues with a slow oxidation rate.

The partial radial distribution functions (RDF) is used to characterize the structure of the formed oxide film. Figure 8 shows the partial RDFs for the total oxide film with an inset with the RDFs for the central part of the oxide film at the end of the simulation. For the mean $\mathrm{Si}-$ O bond length, the position of the first peak is found at $1.575 \AA$ which is very close to the experimental values of $\sim 1.61 \AA$ [50][51][52]. After the first peak, several plateau-shaped revealing non-defined orders are observed. Therefore, it indicates that the oxide film has an amorphous structure. The $\mathrm{Si}-\mathrm{Si}$ distances and the nearest-neighbor $\mathrm{O}-\mathrm{O}$ are observed to be $2.325 \AA$ and $2.675 \AA$, respectively. These values are quite close to the experimental results: 
$2.35 \AA$ for $\mathrm{Si}$-Si distance and $2.65 \AA$ for the nearest-neighbor O-O [53]. A second peak for the Si-Si partial RDF appears at $3.825 \AA$ which also agrees with the simulation results [54].

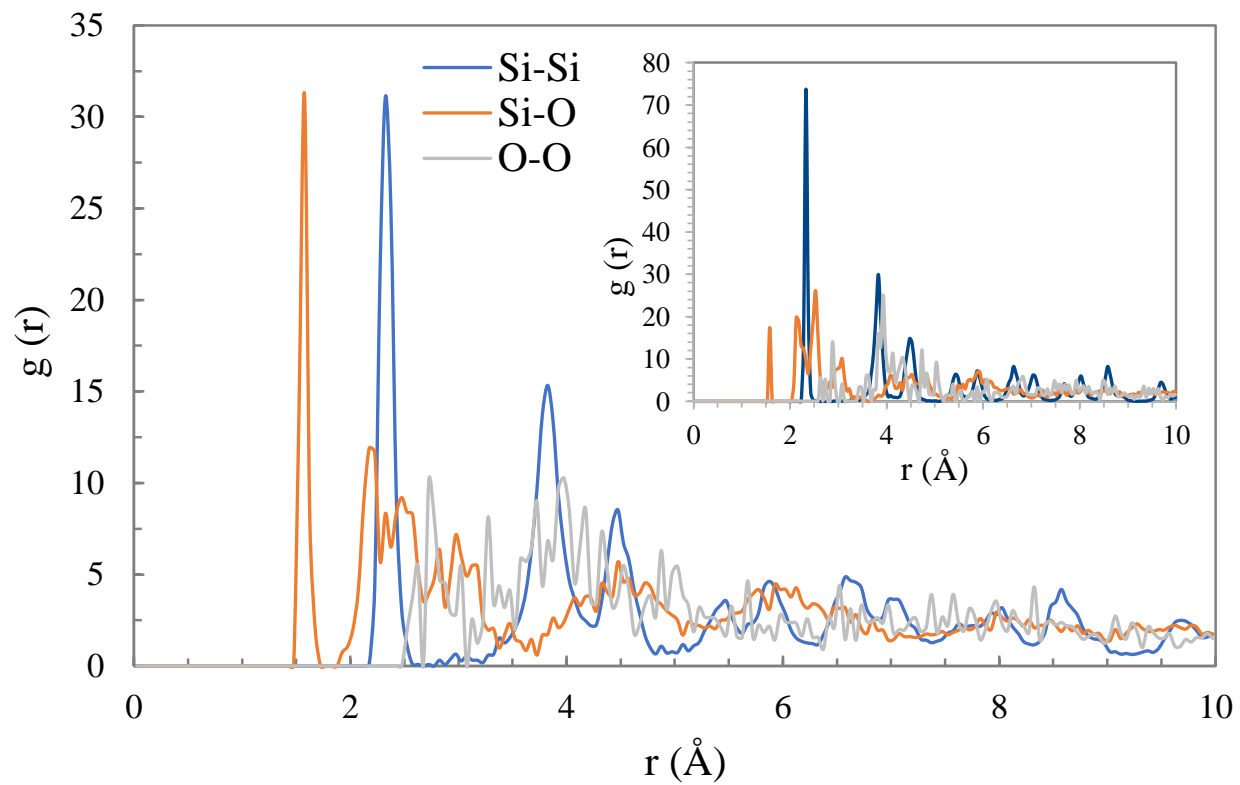

Figure 8. Partial radial distribution functions in the oxide film

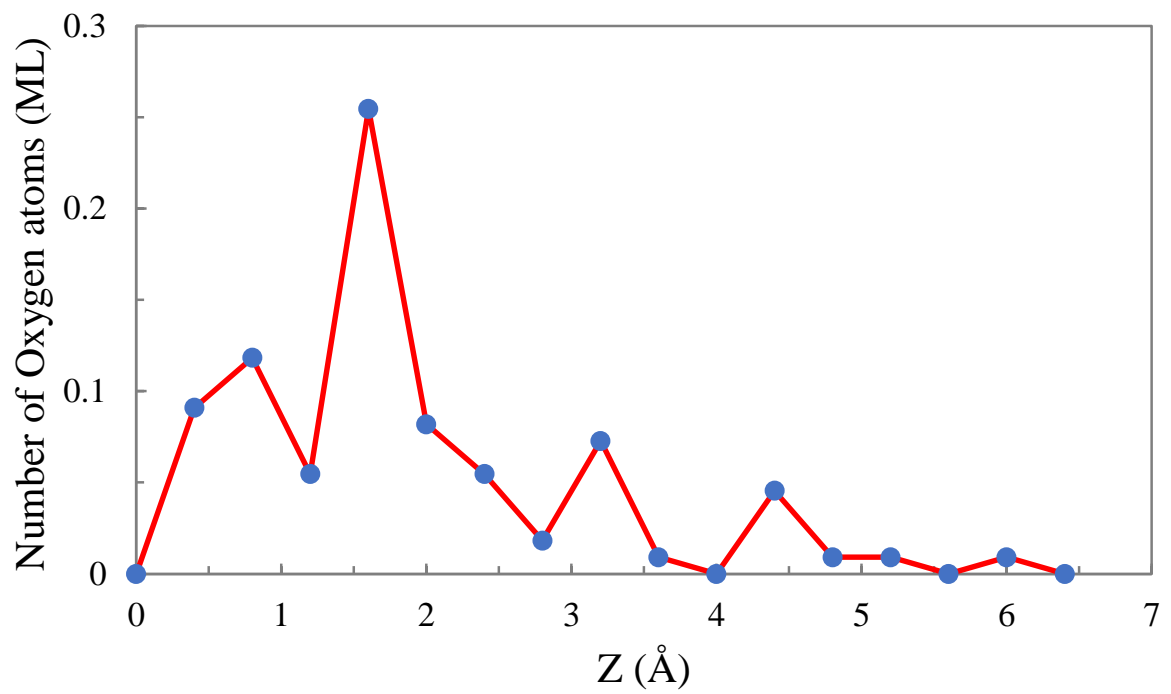

Figure 9. Oxygen atoms distributions below Si surface at $400 \mathrm{ps} . \mathrm{Z}$ is the depth below the surface and its origin is taken as the initial surface position 


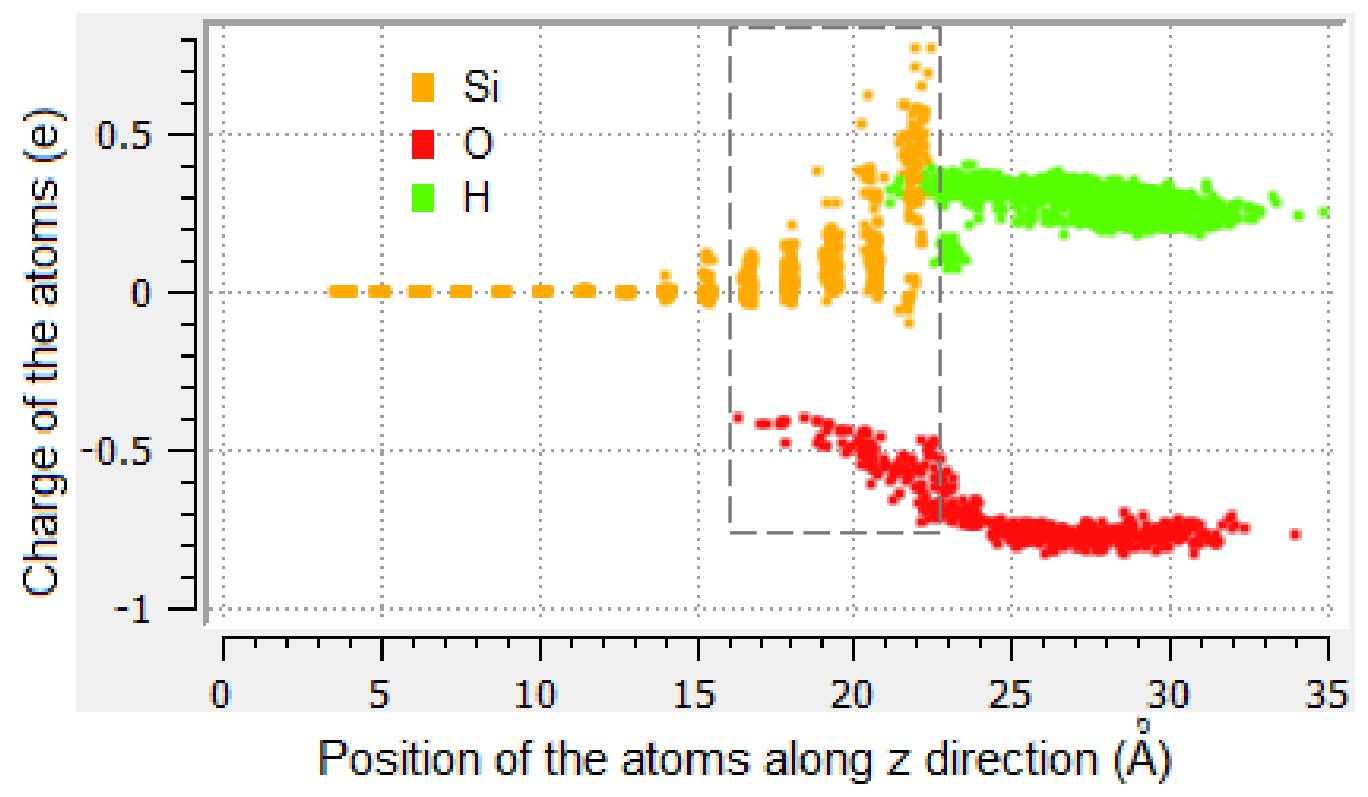

Figure 10. Distribution of atomic charges after 400 ps

We have also studied the oxygen distribution in the oxide film along z-direction which is shown in Figure 9. The number of $\mathrm{O}$ atoms is summed every $0.4 \AA$ sized bin. The zero position of $\mathrm{Z}$ refers to the initial surface position. The maximum number of oxygen atoms is found at a depth of 1.6 $\AA$. The density of the oxygen shows less in the deeper positions of the oxide film. The atomic charge distribution at the end of the simulation is shown in Figure 10. The charge of the silicon atoms outside the oxide film fluctuates slightly around $0 e$ while the oxygen atoms and the hydrogen atoms have a charge of fluctuating around $-0.80 e$ and +0.30 $e$ respectively. These charges are very close to the charges obtained for the bulk of water. It is observed that the charge of the oxidized silicon atoms increases from the bottom part to the upper part of the oxide film and the maximum charge is found $\sim+0.77 e$ at around $22.5 \AA$. The same behavior is observed for the charge distribution of oxygen in the oxide film. Its charge decreases from the upper part to the bottom part of the oxide film until it reaches its minimum value of $\sim-0.41 e$ at around $17 \AA$. Therefore, it can be said that there is a charge transfer between the silicon atoms and the oxygen atoms in the oxide zone.

\subsection{Effect of the Electric Field}

The dependence of the oxide height as a function of the oxidation time for different values of the electric field is presented in Figure 11. We have varied the electric field from $1.5 \mathrm{~V} / \mathrm{nm}$ to $7 \mathrm{~V} / \mathrm{nm}$. All the curves show similar characteristics as explained in section 3.1. We observe a fast growth of the oxide film at the very beginning then it slows down. We notice that increasing the field intensity sped up the process and the kinetics of the reaction. The oxide 
height grows layer by layer fashion. We also find the linear dependency of the oxide thickness with the electric field intensity (Figure 12). This result agrees with the observations of Montserrat Calleja et al. [55], which shows that the thickness of the oxide layer on silicon (100) surface increases linearly with the electric field.

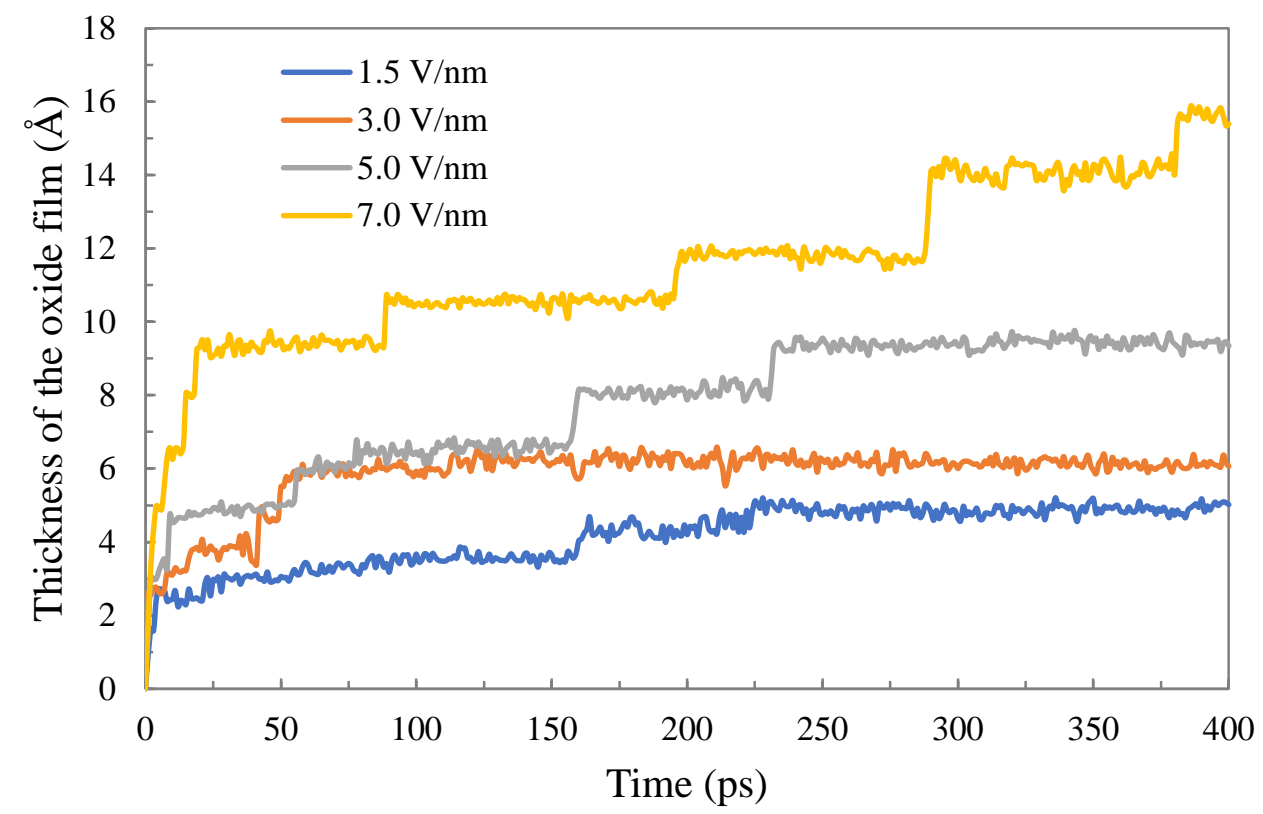

Figure 11. Evolution of oxide film thickness for various electric field intensities.

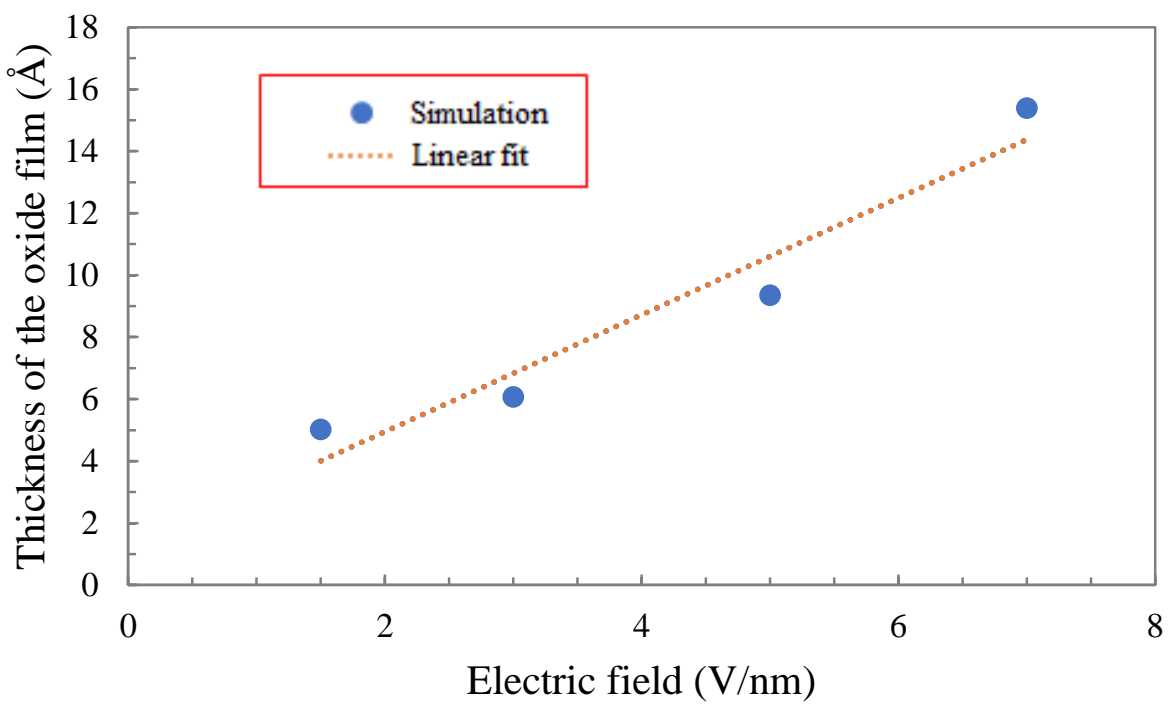

Figure 12. The thickness of the oxide film as a function of the electric field. 
Evolution of $\mathrm{H}_{2} \mathrm{O}$

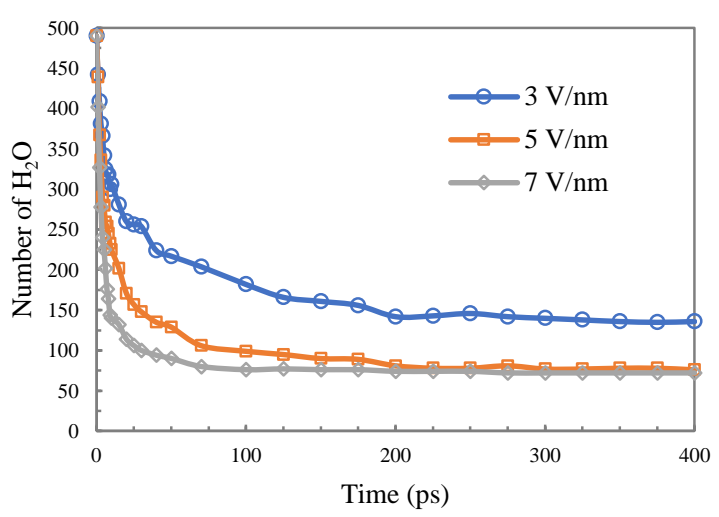

Evolution of $\mathrm{OH}^{-}$

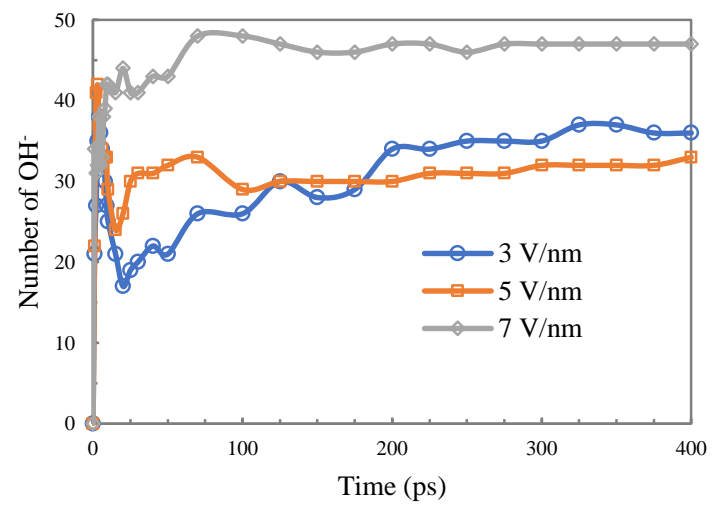

Evolution of $\mathrm{H}_{3} \mathrm{O}^{+}$

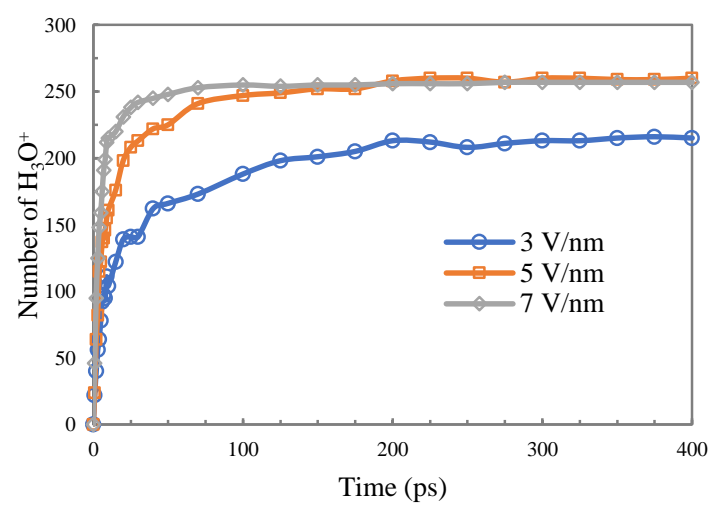

Evolution of $\mathrm{H}^{+}$

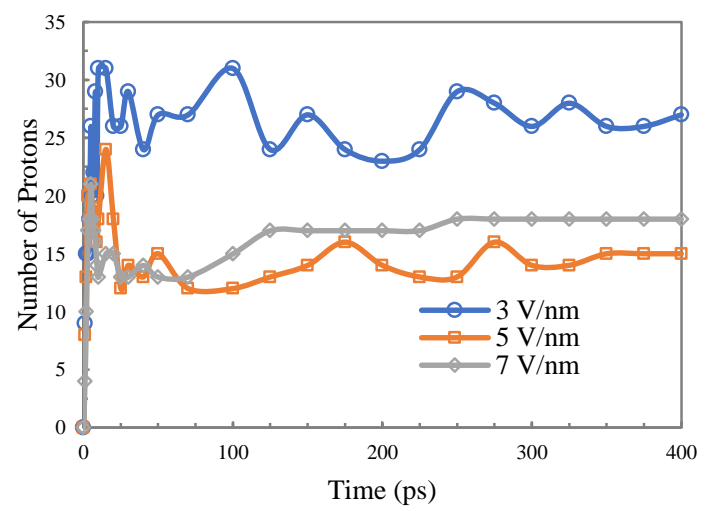

Figure 13. Evolution of the chemical compositions over time for the different electric fields.

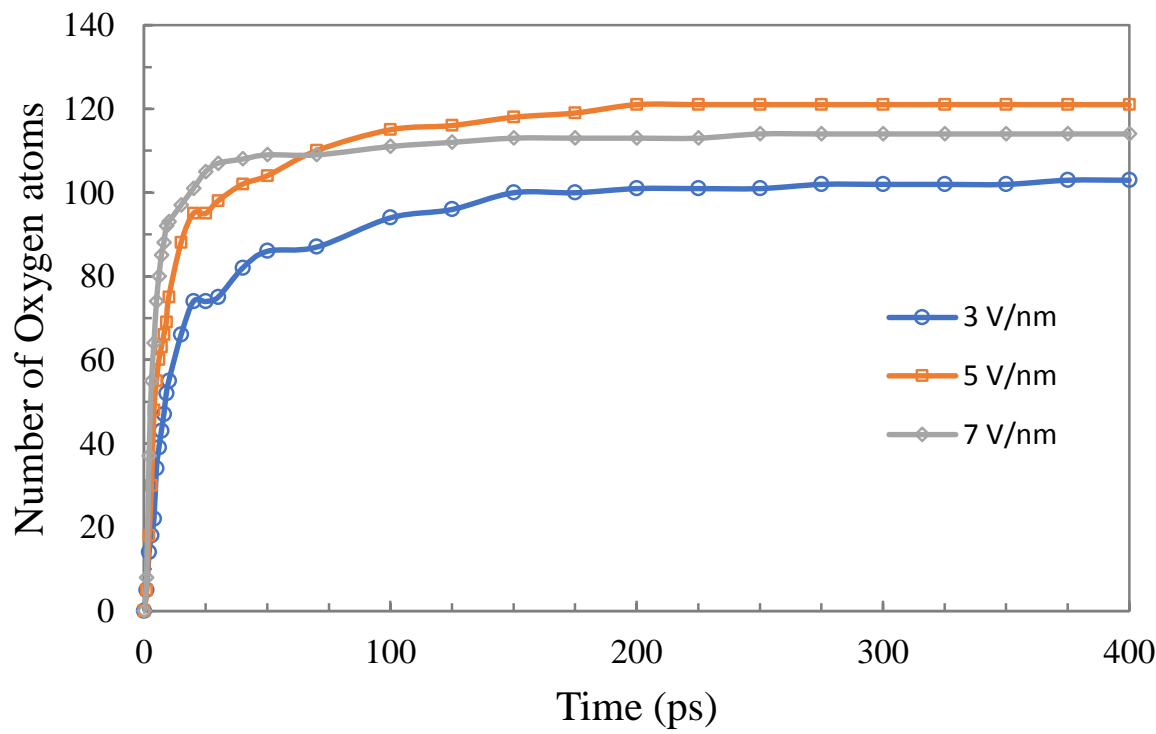

Figure 14. Evolution of the number of oxygen atoms over time for the different electric fields. 
The progression of the $\mathrm{H}_{2} \mathrm{O}, \mathrm{H}_{3} \mathrm{O}^{+}, \mathrm{OH}^{-}$, and $\mathrm{H}^{+}$) over time for the various electric fields is presented in Figure 13. We notice that more water molecules are dissociated when the electric field is higher. The same feature is observed for the formation of $\mathrm{H}_{3} \mathrm{O}^{+}$. Increasing the electric field, it promotes the formation of $\mathrm{H}_{3} \mathrm{O}^{+}$from protons and $\mathrm{H}_{2} \mathrm{O}$. It is also found that for the higher electric field $(7 \mathrm{~V} / \mathrm{nm})$, the number of $\mathrm{OH}^{-}$is generated even more. Interestingly, there is a small rise in $\mathrm{OH}^{-}$number at $3 \mathrm{~V} / \mathrm{nm}$ than that of $5 \mathrm{~V} / \mathrm{nm}$ after around $175 \mathrm{ps}$. For the case of $\mathrm{H}^{+}$generation, it shows the opposite trend, i.e higher values of $\mathrm{H}^{+}$for the lower electric field $(3 \mathrm{~V} / \mathrm{nm})$. Again, it is found that the $\mathrm{H}+$ values increases slightly for 3 $\mathrm{V} / \mathrm{nm}$ than that of $5 \mathrm{~V} / \mathrm{nm}$ after around $25 \mathrm{ps}$. We also observe that the number of oxygen atoms present in the oxide film follows an identical trend for all the electric fields (Figure 14).

\subsection{Effect of the Relative Humidity (RH)}

The thickness of the water layer adsorbed on the surface depends on the relative humidity (RH). M. Luna et al. studied the effect of the relative humidity on the thickness of the adsorbed water and established a relationship between them [44]. They found that the thickness of the adsorbed water layer increases with the relative humidity and the increment is higher for the larger RH values. Considering the formulation given by them (Figure 2 in ref. 44), we have constructed the simulation models with different water layers covered by the silicon substrate. Then we have investigated the oxide growth with respect to the relative humidity during the oxidation process. By applying an electric field of $0.5 \mathrm{~V} / \AA$ for a time of 400 picoseconds, Figure 15 represents the height of the oxides with respect to the different relative humidity (20\% to $90 \%)$.

The oxidation occurs in various humid environments and the $\mathrm{RH}$ values influence the height of the oxide film. Figure 16 shows two different characteristics of oxide growth for various $\mathrm{RH}$ values. In the range $20-40 \% \mathrm{RH}$, there is no significant changes in oxide height. This is because the amount of adsorbed water on the surface does not vary much for the lower values of RH. Beyond $40 \% \mathrm{RH}$, a linear characteristic of the oxide growth with the relative humidity is observed. The height of the oxide film rises from 2.8333 to $9.3503 \AA$ on varying the $\mathrm{RH}$ ( $40 \%$ to $90 \%$ ) with a growth factor of $0.13 \AA / \%$. The same behavior was experimentally observed by Cristiano Albonetti et al. [17]. 


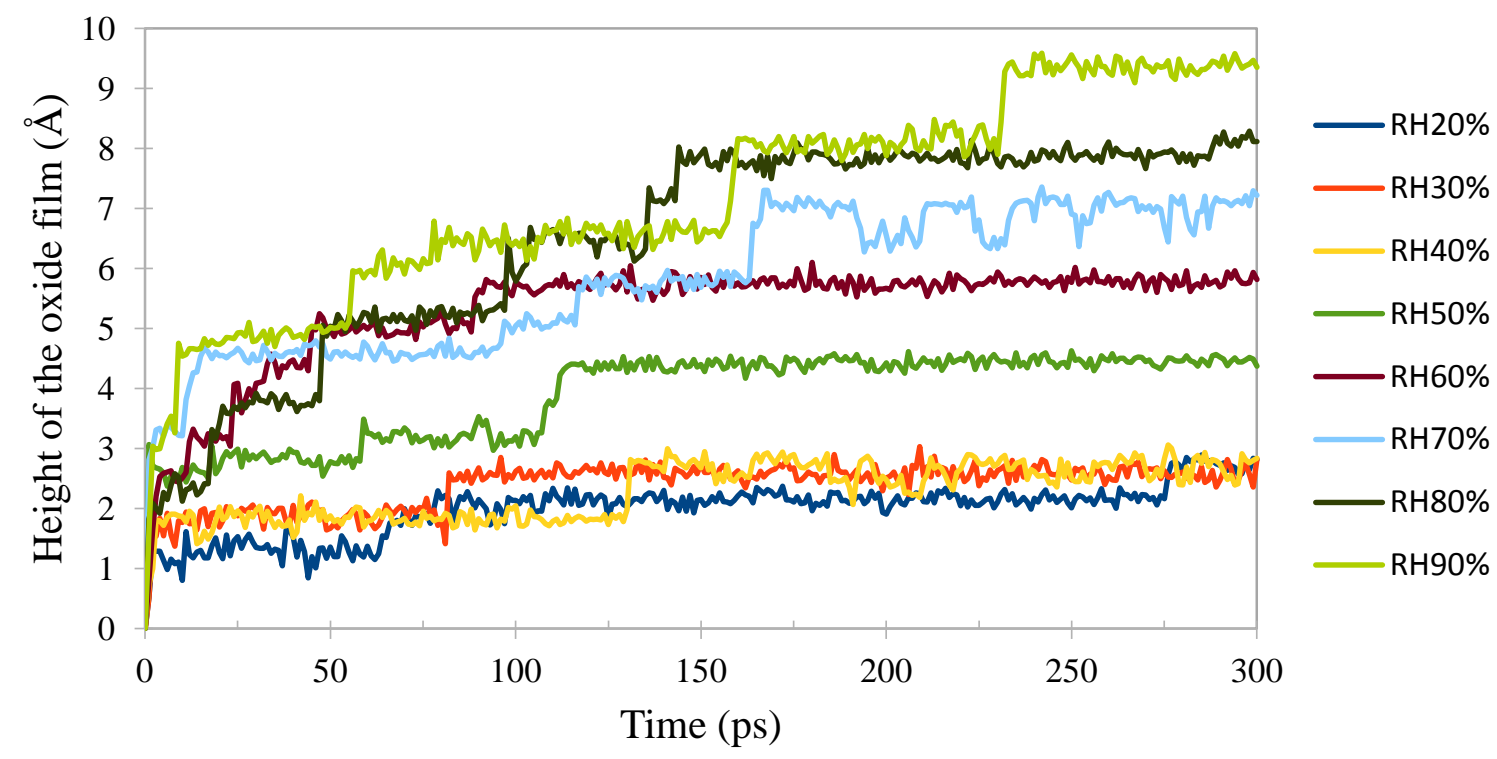

Figure 15. Evolution of oxide film for different relative humidity $(\mathrm{RH})$.

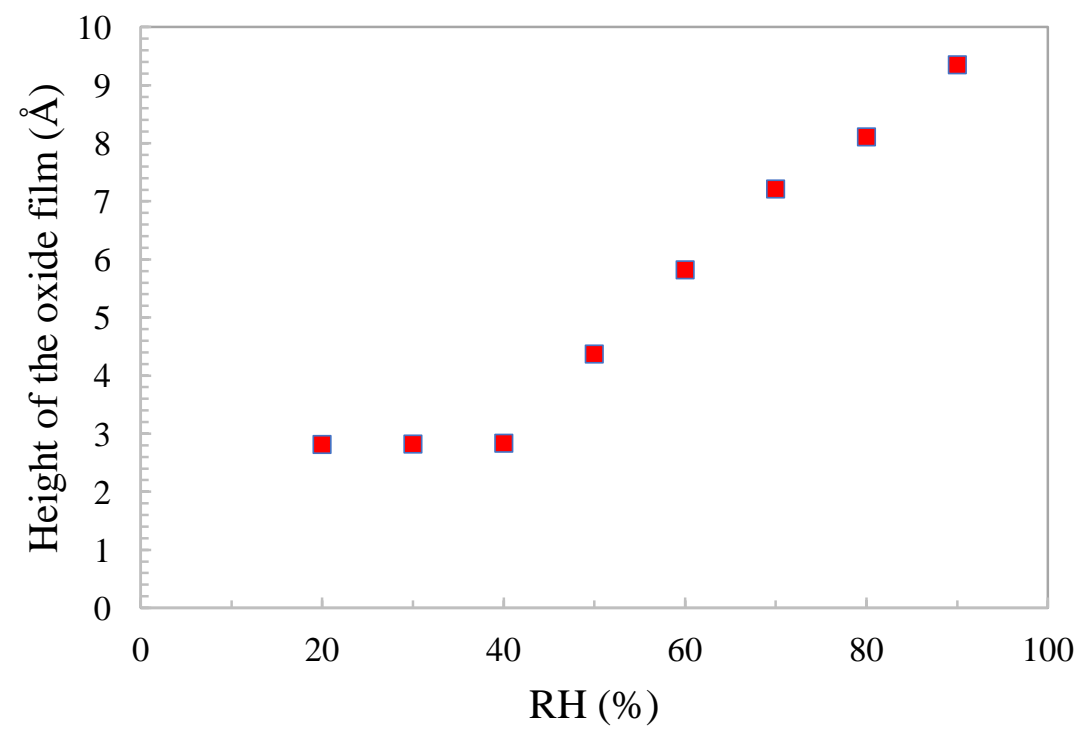

Figure 16. The height of the oxide film as a function of the relative humidity.

\section{Conclusions}

The ReaxFF MD simulation results reliably explain the oxidation process of silicon (100) with an applied electric field, which is the main mechanism of nanoelectrode lithography. We have observed the adsorption of the water molecules on the Si surfaces and their dissociation into $\mathrm{OH}^{-}$and $\mathrm{H}_{3} \mathrm{O}^{+}$at the first stage of the process. Again, the $\mathrm{OH}$ groups are adsorbed on the $\mathrm{Si}$ surfaces and then dissociate to release the $\mathrm{O}$ atoms which form the $\mathrm{Si}-\mathrm{O}-\mathrm{Si}$ bonds, making the surfaces oxidized. Higher oxidation rate is found at the very beginning and the rate slows down over the period. The accumulation of oxygen atoms in the oxide film is found in layer 
by layer fashion. The number of the oxygen atoms is observed less in the deeper positions of the oxide film and the RDF analysis suggests the oxide film as an amorphous structure. The charge distribution of the atoms has been analyzed. The charge transfers between the silicon atoms and the oxygen atoms in the oxide zone are identified. However, it is observed that there is a linear dependency of the oxide thickness with the intensity of the electric field. The higher electric field can make the surface more oxidized. Similar characteristic is also observed for the higher RH values. These results are in good agreement with the experimental observations.

\section{Acknowledgement}

The authors gratefully acknowledge the financial support from the EPSRC (UK) $(\mathrm{EP} / \mathrm{K} 018345 / 1)$ for this research.

\section{Data statement}

All data underpinning this publication will be available from the University of Strathclyde KnowledgeBase at https://doi.org/10.15129/b5a4fdb7-ddc0-431a-a3c5-d2d9a28df99f.

\section{References}

[1] J.A. Dagata, J. Bennett, J. Schneir, M.T. Postek, H.H. Harary, C.J. Evans, Modification of hydrogen-passivated silicon by a scanning tunneling microscope operating in air, Applied Physics Letters. 56 (2002) 2001-2003. doi:10.1063/1.102999.

[2] H. Sugimura, N. Nakagiri, N. Ichinose, Area-selective formation of an organosilane monolayer on silicon oxide nanopatterns fabricated by scanning probe anodization, Applied Physics Letters. 3686 (1995) 3686. doi:10.1063/1.114141.

[3] H. Sugimura, N. Nakagiri, Area selective deposition of gold on silicon surface patterned by tip-induced anodization in scanning probe microcopy, Applied Physics Letters. 66 (1995) 1430-1431. doi:10.1063/1.113268.

[4] C. Obermair, M. Kress, A. Wagner, T. Schimmel, Reversible mechanoelectrochemical writing of metallic nanostructures with the tip of an atomic force microscope, Beilstein Journal of Nanotechnology. 3 (2012) 824-830. doi:10.3762/bjnano.3.92.

[5] R. V. Martínez, N.S. Losilla, J. Martínez, Y. Huttel, R. Garcia, Patterning polymeric structures with $2 \mathrm{~nm}$ resolution at $3 \mathrm{~nm}$ half pitch in ambient conditions, Nano Letters. 7 (2007) 1846-1850. doi:10.1021/n1070328r.

[6] S.D. Hutagalung, K.C. Lew, T. Darsono, Nanoscale patterning by AFM lithography and its application on the fabrication of silicon nanowire devices, in: Sains Malaysiana, 2014: pp. 267-272. 
[7] P.A. Fontaine, E. Dubois, D. Stiévenard, Characterization of scanning tunneling microscopy and atomic force microscopy-based techniques for nanolithography on hydrogen-passivated silicon, Journal of Applied Physics. 84 (1998) 1776-1781. doi:10.1063/1.368334.

[8] Y.K. Ryu, R. Garcia, Advanced oxidation scanning probe lithography, Nanotechnology. 28 (2017). doi:10.1088/1361-6528/aa5651.

[9] M. Pea, M. De Seta, L. Di Gaspare, V. Mišeikis, C. Coletti, A. Notargiacomo, Scanning probe assisted local oxidation nanolithography of CVD grown graphene on Ge(100), in: IEEE 18th International Conference on Nanotechnology (IEEE-NANO), 2018: pp. 1-2. doi:10.1109/NANO.2018.8626395.

[10] N. Balke, S. Jesse, A.P. Baddorf, A. Kumar, G.M. Veith, S. V. Kalinin, A. Tselev, T.M. Arruda, Toward Quantitative Electrochemical Measurements on the Nanoscale by Scanning Probe Microscopy: Environmental and Current Spreading Effects, ACS Nano. 7 (2013) 8175-8182. doi:10.1021/nn4034772.

[11] H. Liu, S. Hoeppener, U.S. Schubert, Nanoscale Materials Patterning by Local Electrochemical Lithography, Advanced Engineering Materials. 18 (2016) 890-902. doi:10.1002/adem.201500486.

[12] H. Liu, S. Hoeppener, U.S. Schubert, Reversible Nanopatterning on Polypyrrole Films by Atomic Force Microscope Electrochemical Lithography, Advanced Functional Materials. 26 (2016) 614-619. doi:10.1002/adfm.201503834.

[13] S. Hoeppener, R. Maoz, J. Sagiv, Constructive microlithography: Electrochemical printing of monolayer template patterns extends constructive nanolithography to the micrometer-millimeter dimension range, Nano Letters. 3 (2003) 761-767. doi:10.1021/n10341761.

[14] M. Cavallini, P. Mei, F. Biscarini, R. García, Parallel writing by local oxidation nanolithography with submicrometer resolution, Applied Physics Letters. 83 (2003) 5286-5288. doi:10.1063/1.1633685.

[15] A. Yokoo, Nanoelectrode lithography, Japanese Journal of Applied Physics, Part 2: Letters. 42 (2003) L92-L94. doi:10.1143/JJAP.42.L92.

[16] Y.F. Li, K.H. Chen, Y. Ootera, H. Toshiyoshi, H. Fujita, Nanoelectrode lithography using flexible conductive molds, Applied Physics A: Materials Science and Processing. 121 (2015) 363-370. doi:10.1007/s00339-015-9138-8.

[17] C. Albonetti, J. Martinez, N.S. Losilla, P. Greco, M. Cavallini, F. Borgatti, M. Montecchi, L. Pasquali, R. Garcia, F. Biscarini, Parallel-local anodic oxidation of silicon surfaces by soft stamps, Nanotechnology. 19 (2008). doi:10.1088/09574484/19/43/435303.

[18] N.S. Losilla, J. Martínez, R. García, Large area nanoscale patterning of silicon surfaces by parallel local oxidation, Nanotechnology. 20 (2009) 1-5. doi:10.1088/09574484/20/47/475304.

[19] A. Yokoo, S. Sasaki, Oxidation patterning of GaAs by nanoelectrode lithography, Japanese Journal of Applied Physics, Part 1: Regular Papers and Short Notes and Review Papers. 44 (2005) 1119-1122. doi:10.1143/JJAP.44.1119.

[20] Y. Okada, Y. Iuchi, M. Kawabe, J.S. Harris, Basic properties of GaAs oxide generated 
by scanning probe microscope tip-induced nano-oxidation process, Journal of Applied Physics. 88 (2000) 1136-1140. doi:10.1063/1.373788.

[21] N.S. Losilla, J. Martinez, E. Bystrenova, P. Greco, F. Biscarini, R. García, Patterning pentacene surfaces by local oxidation nanolithography, Ultramicroscopy. 110 (2010) 729-732. doi:10.1016/j.ultramic.2010.02.040.

[22] J.N. Israelachvili, Intermolecular and Surface Forces, 3rd ed., Academic Press, London, 2011. http://ebooks.cambridge.org/ref/id/CBO9781107415324A009.

[23] L. Filipovic, S. Selberherr, Electric Field Based Simulations of Local Oxidation Nanolithography Using Atomic Force Microscopy in a Level Set Environment, ECS Transactions. 49 (2012) 265-272. doi:10.1149/04901.0265ecst.

[24] A. Notargiacomo, Assembling uniform oxide lines and layers by overlapping dots and lines using AFM local oxidation, in: 2009: pp. 907-910.

[25] J. Cui, X. Yang, X. Wang, P. Yi, W. Wang, X. Mei, B. Theogene, H. Xie, X. He, 3-D finite element calculation of electric field enhancement for nanostructures fabrication mechanism on silicon surface with AFM tip induced local anodic oxidation, Integrated Ferroelectrics. 190 (2018) 129-141. doi:10.1080/10584587.2018.1457346.

[26] T. Cramer, F. Zerbetto, R. García, Molecular mechanism of water bridge buildup: Field-induced formation of nanoscale menisci, Langmuir. 24 (2008) 6116-6120. doi:10.1021/la800220r.

[27] C.D. Daub, D. Bratko, K. Leung, A. Luzar, Electrowetting at the nanoscale, Journal of Physical Chemistry C. 111 (2007) 505-509. doi:10.1021/jp067395e.

[28] A.C.T. Van Duin, S. Dasgupta, F. Lorant, W.A. Goddard, ReaxFF: A Reactive Force Field for Hydrocarbons, J. Phys. Chem. A. 105 (2001) 9396-9409. doi:10.1021/jp004368u.

[29] U. Khalilov, G. Pourtois, S. Huygh, A.C.T. Van Duin, E.C. Neyts, A. Bogaerts, New mechanism for oxidation of native silicon oxide, Journal of Physical Chemistry C. 117 (2013) 9819-9825. doi:10.1021/jp400433u.

[30] S. Dumpala, S.R. Broderick, U. Khalilov, E.C. Neyts, A.C.T. Van Duin, J. Provine, R.T. Howe, K. Rajan, Integrated atomistic chemical imaging and reactive force field molecular dynamic simulations on silicon oxidation, Applied Physics Letters. 106 (2015). doi:10.1063/1.4905442.

[31] J. Wen, T. Ma, W. Zhang, A.C.T. Van Duin, X. Lu, Surface orientation and temperature effects on the interaction of silicon with water: Molecular dynamics simulations using ReaxFF reactive force field, Journal of Physical Chemistry A. 121 (2017) 587-594. doi:10.1021/acs.jpca.6b11310.

[32] Y. Sun, Y. Liu, X. Chen, Z. Zhai, F. Xu, Y. Liu, Micromechanism of oxygen transport during initial stage oxidation in $\mathrm{Si}(100)$ surface: A ReaxFF molecular dynamics simulation study, Applied Surface Science. $406 \quad$ (2017) 178-185. doi:10.1016/j.apsusc.2017.01.302.

[33] Y. Sun, X.-F. Chen, Z. Zhai, S.-H. Tian, Y.-L. Liu, S. Izumi, Initial stage oxidation on nano-trenched Si(1 00 0) surface, Journal of Physics D: Applied Physics. 51 (2018). doi:10.1088/1361-6463/aa99ab. 
[34] M.A. Pamungkas, B.H. Kim, K.R. Lee, Reactive molecular dynamic simulations of early stage of wet oxidation of Si (001) surface, Journal of Applied Physics. 114 (2013). doi:10.1063/1.4818941.

[35] M.A. Pamungkas, M. Joe, B.H. Kim, K.R. Lee, Reactive molecular dynamics simulation of early stage of dry oxidation of Si (100) surface, Journal of Applied Physics. 110 (2011). doi:10.1063/1.3632968.

[36] J. Wen, T. Ma, W. Zhang, G. Psofogiannakis, A.C.T. van Duin, L. Chen, L. Qian, Y. $\mathrm{Hu}, \mathrm{X}$. Lu, Atomic insight into tribochemical wear mechanism of silicon at the $\mathrm{Si} / \mathrm{SiO} 2$ interface in aqueous environment: Molecular dynamics simulations using ReaxFF reactive force field, Applied Surface Science. 390 (2016) 216-223. doi:10.1016/j.apsusc.2016.08.082.

[37] G. Psofogiannakis, A.C.T. Van Duin, Development of a ReaxFF reactive force field for $\mathrm{Si} / \mathrm{Ge} / \mathrm{H}$ systems and application to atomic hydrogen bombardment of $\mathrm{Si}, \mathrm{Ge}$, and SiGe (100) surfaces, Surface Science. $646 \quad$ (2016) 253-260. doi:10.1016/j.susc.2015.08.019.

[38] A.C.T. van Duin, C. Zou, K. Joshi, W.A. Goddard, V. Bryantsev, A Reaxff Reactive Force-field for Proton Transfer Reactions in Bulk Water and its Applications to Heterogeneous Catalysis, in: Computional Catalysis. RSC Catalysis Series, Royal Society of Chemistry, Cambridge, 2013: pp. 223-243. doi:10.1039/978184973490500223 .

[39] A.K. Rap, W.A.G. Iii, Charge Equilibration for Molecular Dynamics Simulations, Journal of Physical Chemistry. 95 (1991) 3358-3363.

[40] Aiichiro Nakano, Parallel multilevel preconditioned conjugate-gradient approach to variable-charge molecular dynamics, Computer Physics Communications. 104 (1997) 59-69. doi:10.1016/S0010-4655(97)00041-6.

[41] S. Plimpton, Fast Parallel Algorithms for Short-Range Molecular Dynamics, Journal of Computational Physics. 117 (1995) 1-42. doi:10.1006/jcph.1995.1039.

[42] O. Assowe, O. Politano, V. Vignal, P. Arnoux, B. Diawara, O. Verners, A.C.T. Van Duin, Reactive molecular dynamics of the initial oxidation stages of Ni(111) in pure water: Effect of an applied electric field, Journal of Physical Chemistry A. 116 (2012) 11796-11805. doi:10.1021/jp306932a.

[43] J. Chen, T.J. Martínez, Charge conservation in electronegativity equalization and its implications for the electrostatic properties of fluctuating-charge models, Journal of Chemical Physics. 131 (2009) 044114-1-044114-3. doi:10.1063/1.3183167.

[44] M. Luna, J. Colchero, A.M. Baró, Intermittent contact scanning force microscopy: The role of the liquid necks, Applied Physics Letters. 72 (1998) 3461-3463. doi:10.1063/1.121666.

[45] A. Stukowski, Visualization and analysis of atomistic simulation data with OVITO-the Open Visualization Tool, Modelling and Simulation in Materials Science and Engineering. 18 (2010) 015012. doi:10.1088/0965-0393/18/1/015012.

[46] R. Garcia, M. Calleja, H. Rohrer, Patterning of silicon surfaces with noncontact atomic force microscopy: Field-induced formation of nanometer-size water bridges, Journal of Applied Physics. 86 (1999) 1898-1903. doi:10.1063/1.370985. 
[47] Y. Chabal, Hydride formation on the Si (100): H2O surface, Physical Review B. 29 (1984) 3677-3680. http://prb.aps.org/abstract/PRB/v29/i6/p3677_1.

[48] M. Chander, Y.Z. Li, J.C. Patrin, J.H. Weaver, Si(100)-(2×1) surface defects and dissociative and nondissociative adsorption of $\mathrm{H} 2 \mathrm{O}$ studied with scanning tunneling microscopy, Physical Review B. 48 (1993) 2493-2499. doi:10.1103/PhysRevB.48.2493.

[49] D. Graf, M. Frommenwiler, P. Studerus, T. Ihn, K. Ensslin, D.C. Driscoll, A.C. Gossard, Local oxidation of $\mathrm{Ga}[\mathrm{Al}] \mathrm{As}$ heterostructures with modulated tip-sample voltages, Journal of Applied Physics. (2006). doi:10.1063/1.2176162.

[50] A.C. Wright, Neutron scattering from vitreous silica. V. The structure of vitreous silica: What have we learned from 60 years of diffraction studies?, Journal of NonCrystalline Solids. 179 (1994) 84-115. doi:10.1016/0022-3093(94)90687-4.

[51] T. Uchiyama, M. Tsukada, Atomic and electronic structures of oxygen-adsorbed Si(001) surfaces, Physical Review B. 53 (1996) 7917-7922. doi:10.1016/00396028(96)80076-8.

[52] T. Uchiyama, M. Tsukada, Scanning-tunneling-microscopy images of oxygen adsorption on the Si(001) surface, Physical Review B. 55 (1997) 9356-9359. doi:10.1103/PhysRevB.55.9356.

[53] M. V. Coleman, D.J.D. Thomas, The Structure of Silicon Oxide Films, Physica Status Solidi (B). 22 (1967) 593-602. doi:10.1002/pssb.19670220231.

[54] W. D. Luedtke and Uzi Landman, Preparation, structure, dynamics, and energetics of amorphous silicon: A molecular-dynamics study, Physical Review B. 40 (1989) 11641174. doi:10.1103/PhysRevB.40.1164.

[55] M. Calleja, R. García, Nano-oxidation of silicon surfaces by noncontact atomic-force microscopy: Size dependence on voltage and pulse duration, Applied Physics Letters. 76 (2000) 3427-3429. doi:10.1063/1.126856. 